\title{
Diagnosis and management of vasospasm
}

\section{Luciana Mascia* and Lorenzo Del Sorbo}

\author{
Address: Dipartimento di Anestesiologia e Rianimazione, Università di Torino, Ospedale S Giovanni Battista, Corso Dogliotti 14, \\ 10126 Torino, Italy \\ *Corresponding author: Luciana Mascia (luciana.mascia@unito.it) \\ FI000 Medicine Reports 2009, I:33 (doi:I0.34I0/MI-33)
}

The electronic version of this article is the complete one and can be found at: http://F/000.com/Reports/Medicine/content/I/33

\begin{abstract}
An overview of the main features of cerebral vasospasm is provided in this report, highlighting the possible future direction of development in the diagnosis and management of this severe complication of aneurysmal subarachnoid hemorrhage.
\end{abstract}

\section{Introduction and context}

Vasospasm is one of the most dreaded acute complications, developing 4-15 days after aneurysmal subarachnoid hemorrhage (SAH). It is characterized by a pathological, diffuse, and long-lasting narrowing of the vessel lumen of large-capacity cerebral arteries at the base of the brain either close or distal to the site of bleeding, and is associated with a reduced perfusion of the territories distal to the affected vessel. Angiographic vasospasm occurs in 30-70\% of patients with SAH, but it leads to clinically evident signs and symptoms in 20$30 \%$ of patients who experience delayed ischemic neurological deficits. About half of this latter group of patients suffer severe permanent neurological dysfunction or death [1].

Vasospasm affects all layers of the involved arterial wall of the cerebral vessels. A proliferative inflammatory arteriopathy is the pathological feature of cerebral vasospasm. In fact, the adventitia is infiltrated with inflammatory cells and the neuronal endings are damaged. The media is thickened and fibrotic, with an increased proliferation of smooth muscle cells. The intima shows a disruption of the internal elastic lamina [2].

An important predictor of the occurrence of vasospasm after SAH is the amount of blood present around the cerebral arteries of the circle of Willis. The Fisher computed-tomography rating scale of $\mathrm{SAH}$, and recent modified versions, have demonstrated a strong clinical correlation with the development of clinically significant vasospasm [3-5]. Patients with thick basal cistern blood and the presence of intraventricular blood in the lateral ventricles carry the highest risk. Other risk factors include young age, hypertension, smoking, and cocaine use [6].

It has been clearly demonstrated that prolonged exposure of cerebral arteries to perivascular blood is necessary for the development of vasospasm. However, it has been impossible until now to identify a single causative molecule as the culprit of vasospasm. Nonetheless, there is evidence that a few agents, such as oxyhemoglobin, nitric oxide, and endothelin-1, may be contributors to this pathological event.

Oxyhemoglobin, a product of auto-oxydation of hemoglobin, can directly or indirectly induce arterial vasoconstriction, especially if the oxygen-free radical scavenging systems are insufficient. Oxyhemoglobin can also exert a scavenging effect toward nitric oxide (a potent vasodilator whose depletion has been demonstrated during vasospasm) and can stimulate endothelial cells to produce endothelin-1. Endothelin-1 causes the most potent and long-lasting vasoconstrictor effect, which is also associated with morphological changes, mimicking the delayed cerebral vasospasm. It has been demonstrated that endothelin-1 levels are increased, not only in the cerebrospinal fluid during $\mathrm{SAH}$, but also during severe neuronal injury (when caused independently from vasospasm or the primary bleeding event). 
Furthermore, endothelin levels change in parallel with neurological symptoms, but are not predictive of vasospasm as assessed by transcranial Doppler (TCD). These observations do not exclude a causative role of endothelin-1 for vasospasm but rather suggest that endothelin-1 acts as a marker of cerebral ischemic injury [7-10].

\section{Recent advances Diagnosis}

Angiography of the vessels of the brain is the gold standard for the diagnosis of cerebral vasospasm. However, this procedure is invasive, requires the availability of significant resources, and may cause vessel dissection or thrombosis. Alternative diagnostic tests, such as computed tomographic angiography and TCD, have now been clinically validated [11]. Magnetic resonance imaging, radionuclide imaging, and electroencephalography have also been investigated as diagnostic tools.

TCD is not invasive and can be performed at the bedside. For the middle cerebral artery, TCD has a high specificity with a threshold value ranging between 160 and $200 \mathrm{~cm} / \mathrm{s} \mathrm{[12].} \mathrm{TCD} \mathrm{evaluation} \mathrm{is} \mathrm{recommended} \mathrm{as} \mathrm{a}$ screening tool in high-grade WFNS (World Federation of Neurological Surgeons) scale patients in whom a neurological examination cannot be readily followed to identify those at higher risk [13].

In the most severe cases needing monitoring of intracranial pressure and cerebral perfusion pressure, the use of cerebral microdialysis has been proposed to identify the threshold of anaerobic metabolism (expressed by the lactate/piruvate ratio as an indirect sign of hypoperfusion). Cerebral microdialysis in association with other brain-monitoring techniques may assist in the delivery of targeted therapy for prevention of secondary ischemic injury [14].

\section{Treatment}

Critical care management of patients with aneurysmal SAH aims at improving neurological outcome, and includes the treatment of non-neurological systems affecting the brain; a multi-organ clinical approach instead of a single-organ approach probably represents the optimal way to reach this goal. Indeed, recent studies showed that strategies directed at maintaining normothermia, normoglycemia, and prevention of anemia may improve outcome after SAH. In fact, fever, anemia, and hyperglycemia affect $30-54 \%$ of patients with SAH and are significantly associated with mortality and poor functional outcome [15].
The specific treatment of cerebral vasospasm aims at improving cerebral blood flow with one of two possible approaches: indirect pharmacological protection of the brain tissue or direct mechanical dilation of the vasospastic vessel.

Though not proven by any randomized clinical trial, induced hypertension, hypervolemia, and hemodilution (triple $\mathrm{H}$ therapy) are considered the mainstay of the treatment of vasospasm. This strategy is associated with a high rate of complications however, limiting its usefulness, and has been demonstrated to be ineffective in many patients [16]. A recent investigation, focusing on the effect of each component of triple $\mathrm{H}$ therapy on cerebral blood flow, showed that only vasopressorinduced elevation of mean arterial pressure caused a significant increase of regional cerebral blood flow and brain tissue oxygenation, confirming that cerebral pressure autoregulation is often impaired in these patients [17]. Although there is no proven role for hypervolemia, hypovolemia must be avoided because it increases the risk of delayed infarction [18]. Regarding the hemodilution component, recent studies tried to identify the optimal hemoglobin range and concluded that extreme hemodilution should be avoided, particularly in patients with a cardiac condition [19].

The calcium channel blocker nimodipine is considered the standard of care in aneurysmal SAH patients. Although experimental studies failed to show its ability to prevent angiographic vasospasm, its administration immediately after SAH diagnosis and for 10-15 days thereafter has been shown to improve outcome and reduce cerebral infarction [20].

Several experimental treatments have recently been proposed for the management of cerebral vasospasm (such as, cisternal thrombolysis, surgical removal of the clot, lipid peroxidation inhibitors, and the use of scavengers of hydroxyl radicals), but further evidence is needed to prove their efficacy [21]. Currently, the most promising experimental treatment is the administration of magnesium sulfate, statins, nitric oxide donors, or endothelin-1 antagonists. High-dose magnesium therapy might be efficient as a prophylactic adjacent therapy after SAH to reduce the risk for poor outcome. Nevertheless, because of the high frequency of side effects, patients should be observed in an intensive or intermediate care setting and hypomagnesemia should always be avoided [22].

A meta-analysis based on three small clinical trials showing reduced incidences of vasospasm, delayed ischemic deficits, and mortality, advocates the routine 
therapeutic use of statins after aneurysmal SAH [23]. A phase II clinical trial with an endothelin receptor A antagonist, clazosentan, has demonstrated a reduction in the incidence and severity of angiographic vasospasm from 66 to $23 \%$, while adverse events were comparable to those of placebo [24]. Moreover, another phase II trial, testing an antagonist against the endothelin receptors A and $\mathrm{B}$, showed an improvement in delayed ischemic deficits, occurring in $30 \%$ of patients receiving active treatment and $37 \%$ of patients on placebo [25].

Mechanical dilation of the vasospastic vessel by transluminal cerebral angioplasty has been demonstrated to effectively reverse radiographically confirmed vasospasm [26]. Moreover, with this technique, it is possible to selectively inject vasodilators, such as papaverine and more recently nicardipine, milrinone, and verapamil [27]. Nevertheless, since few long-term outcome studies are available, its superiority to medical management for symptomatic cerebral vasospasm is questionable [28]. Therefore, the use of angioplasty should be reserved for patients who failed to improve with conventional hemodynamic management.

Recently, the effect of prophylactic transluminal balloon angioplasty on cerebral vasospasm in patients with SAH (Fisher grade III) has been investigated in a randomized clinical trial [29]. Fewer patients developed vasospasm after treatment with angioplasty, and there was a significant decrease in the need for therapeutic angioplasty, however, the use of angioplasty did not improve the outcome of these patients.

\section{Implications for clinical practice}

Although knowledge of the pathophysiology of vasospasm after SAH has advanced significantly over the past years, it continues to be a major cause of mortality and morbidity without a known specific treatment.

Recent studies have validated the use of computedtomographic angiography and TCD in the diagnosis of vasospasm, and it has been shown that cerebral microdialysis in association with other brain-monitoring techniques may assist in the delivery of targeted therapy to prevent secondary ischemic injury.

A multi-organ clinical approach to the treatment of cerebral vasospasm is recommended, including the maintenance of normothermia, normoglycemia, and the prevention of anemia.

The efficacy of triple $\mathrm{H}$ therapy remains uncertain and its limitations need to be recognized. Studies into the administration of magnesium sulfate, statins, nitric oxide donors, or endothelin-1 antagonists have, however, proved promising, but further efforts are needed to translate these results into clinical practice in order to improve the neurointensive care management of this severe complication.

Some improvement was seen in preventing vasospasm using prophylactic transluminal balloon angioplasty, but the use of angioplasty should be reserved for those patients who failed to improve with conventional hemodynamic management.

\section{Abbreviations}

SAH, subarachnoid hemorrhage; TCD, transcranial Doppler; WFNS, World Federation of Neurological Surgeons.

\section{Competing interests}

The authors declare that they have no competing interests.

\section{References}

I. Jose IS, Robert WT, Warren RS: Aneurysmal subarachnoid hemorrhage. N Engl J Med 2006, 354:387-96.

2. Pluta RM: Delayed cerebral vasospasm and nitric oxide: review, new hypothesis, and proposed treatment. Pharmacol Ther 2005, 105:23-56.

3. Fisher CM, Kistler JP, Davis JM: Relation of cerebral vasospasm to subarachnoid hemorrhage visualized by computerized tomographic scanning. Neurosurgery 1980, 6:1-9.

4. Claassen J, Bernardini GL, Kreiter K, Bates J, Du YE, Copeland D, Connolly ES, Mayer SA: Effect of cisternal and ventricular blood on risk of delayed cerebral ischemia after subarachnoid hemorrhage: the Fisher scale revisited. Stroke 200I, 32:20I2-20.

5. Frontera JA, Claassen J, Schmidt JM, Wartenberg KE, Temes R, Connolly ES Jr., MacDonald RL, Mayer SA: Prediction of symptomatic vasospasm after subarachnoid hemorrhage: the modified fisher scale. Neurosurgery 2006, 59:21-7.

FI000 Factor 3.0 Recommended

Evaluated by Paul Vespa 26 Sep 2006

6. Qureshi Al, Suri MF, Yahia AM, Suarez Jl, Guterman LR, Hopkins LN, Tamargo RJ: Risk factors for subarachnoid hemorrhage. Neurosurgery 200I, 49:607-I2.

7. Pluta RM: Dysfunction of nitric oxide synthases as a cause and therapeutic target in delayed cerebral vasospasm after SAH. Acta Neurochir Suppl 2008, I04:139-47.

8. Schwartz AY, Sehba FA, Bederson JB: Decreased nitric oxide availability contributes to acute cerebral ischemia after subarachnoid hemorrhage. Neurosurgery 2000, 47:208-I4.

9. Xie A, Aihara Y, Bouryi VA, Nikitina E, Jahromi BS, Zhang ZD, Takahashi M, Macdonald RL: Novel mechanism of endothelin-Iinduced vasospasm after subarachnoid hemorrhage. J Cereb Blood Flow Metab 2007, 27:1692-701.

I0. Mascia L, Fedorko L, Stewart DJ, Mohamed F, terBrugge K, Ranieri VM, Wallace MC: Temporal relationship between endothelin-I concentrations and cerebral vasospasm in patients with aneurysmal subarachnoid hemorrhage. Stroke 200I, 32:I I85-90.

II. Wintermark M, Ko NU, Smith WS, Liu S, Higashida RT, Dillon WP: Vasospasm after subarachnoid hemorrhage: utility of 
perfusion CT and CT angiography on diagnosis and management. Am J Neuroradiol 2006, 27:26-34.

\section{Changes Clinical Practice}

Factor 6.0 Must Read

Evaluated by Giuseppe Citerio 13 Feb 2006

12. Lysakowski C, Walder B, Costanza MC, Tramèr MR: Transcranial Doppler versus angiography in patients with vasospasm due to a ruptured cerebral aneurysm: a systematic review. Stroke 200I, 32:2292-8.

13. Mascia L, Fedorko L, terBrugge K, Filippini C, Pizzio M, Ranieri VM, Wallace MC: The accuracy of transcranial Doppler to detect vasospasm in patients with aneurysmal subarachnoid hemorrhage. Intensive Care Med 2003, 29: 1088-94.

14. Bellander BM, Cantais E, Enblad P, Hutchinson P, Nordström CH, Robertson C, Sahuquillo J, Smith M, Stocchetti N, Ungerstedt U, Unterberg A, Olsen NV: Consensus meeting on microdialysis in neurointensive care. Intensive Care Med 2004, 30:2166-9.

I5. Wartenberg KE, Schmidt JM, Claassen J, Temes RE, Frontera JA, Ostapkovich N, Parra A, Connolly ES, Mayer SA: Impact of medical complications on outcome after subarachnoid hemorrhage. Crit Care Med 2006, 34:6I7-23.

FI000 Factor 3.0 Recommended

Evaluated by Robert Macdonald 08 May 2006

16. Lennihan L, Mayer SA, Fink ME, Beckford A, Paik MC, Zhang H, Wu YC, Klebanoff LM, Raps EC, Solomon RA: Effect of hypervolemic therapy on cerebral blood flow after subarachnoid hemorrhage: a randomized controlled trial. Stroke 2000, 31:383-91.

17. Muench E, Horn P, Bauhuf C, Roth H, Philipps M, Hermann P, Quintel M, Schmiedek P, Vajkoczy P: Effects of hypervolemia and hypertension on regional cerebral blood flow, intracranial pressure, and brain tissue oxygenation after subarachnoid hemorrhage. Crit Care Med 2007, 35:1844-5।.

FI000 Factor 4.8 Must Read

Evaluated by lan Herrick 14 Aug 2007

18. Nelson RJ, Roberts J, Rubin C, Walker V, Ackery DM, Pickard JD: Association of hypovolemia after subarachnoid hemorrhage with computed tomographic scan evidence of raised intracranial pressure. Neurosurgery 1991, 29:178-82.

19. Naidech AM, Jovanovic B, Wartenberg KE, Parra A, Ostapkovich N, Connolly ES, Mayer SA, Commichau C: Higher hemoglobin is associated with improved outcome after subarachnoid hemorrhage. Crit Care Med 2007, 35:2383-9.

20. Dorhout Mees SM, Rinkel GJ, Feigin VL, Algra A, van den Bergh WM, Vermeulen $M$, van Gijn J: Calcium antagonists for aneurysmal subarachnoid haemorrhage. Cochrane Database Syst Rev 2007, 3: CD000277.

2I. Keyrouz SG, Diringer MN: Clinical review: prevention and therapy of vasospasm in subarachnoid hemorrhage. Crit Care 2007, I I:220.

22. Muroi C, Terzic A, Fortunati M, Yonekawa Y, Keller E: Magnesium sulfate in the management of patients with aneurysmal subarachnoid hemorrhage: a randomized, placebo-controlled, dose-adapted trial. Surg Neurol 2008, 69:33-9.

23. Sillberg VA, Wells GA, Perry J]: Do statins improve outcomes and reduce the incidence of vasospasm after aneurysmal subarachnoid hemorrhage: a meta-analysis. Stroke 2008, 39:2622-6

FI000 Factor 6.0 Must Read

Evaluated by Nicolas Bruder 15 Sep 2008

24. Macdonald RL, Kassell NF, Mayer S, Ruefenacht D, Schmiedek P, Weidauer S, Frey A, Roux S, Pasqualin A; CONSCIOUS-I Investigators: Clazosentan to overcome neurological ischemia and infarction occurring after subarachnoid hemorrhage (CONSCIOUS-I): randomized, double-blind, placebo-controlled phase 2 dose-finding trial. Stroke 2008, 39:30I5-2I.

FI000 Factor 3.0 Recommended

Evaluated by Christine Wijman 21 Nov 2008

25. Shaw MD, Vermeulen M, Murray GD, Pickard JD, Bell BA, Teasdale GM: Efficacy and safety of the endothelin, receptor antagonist TAK-044 in treating subarachnoid hemorrhage: a report by the Steering Committee on behalf of the UK/Netherlands/Eire TAK-044 Subarachnoid Haemorrhage Study Group. J Neurosurg 2000, 93:992-7.

26. Jestaedt L, Pham M, Bartsch AJ, Kunze E, Roosen K, Solymosi L, Bendszus $M$ : The impact of balloon angioplasty on the evolution of vasospasm-related infarction after aneurysmal subarachnoid hemorrhage. Neurosurgery 2008, 62:610-7.

27. Barth M, Capelle HH, Weidauer S, Weiss C, Münch E, Thomé C, Luecke T, Schmiedek P, Kasuya H, Vajkoczy P: Effect of nicardipine prolonged-release implants on cerebral vasospasm and clinical outcome after severe aneurysmal subarachnoid hemorrhage: a prospective, randomized, double-blind phase Ila study. Stroke 2007, 38:330-6.

FI000 Factor 6.0 Must Read

Evaluated by Robert Macdonald 09 Feb 2007

28. Polin RS, Coenen VA, Hansen CA, Shin P, Baskaya MK, Nanda A, Kassell NF: Efficacy of transluminal angioplasty for the management of symptomatic cerebral vasospasm following aneurysmal subarachnoid hemorrhage. J Neurosurg 2000, 92:284-90.

29. Zwienenberg-Lee M, Hartman J, Rudisill N, Madden LK, Smith K Eskridge J, Newell D, Verweij B, Bullock MR, Baker A, Coplin W, Mericle R, Dai J, Rocke D, Muizelaar JP; Balloon Prophylaxis for Aneurysmal Vasospasm (BPAV) Study Group: Effect of prophylactic transluminal balloon angioplasty on cerebral vasospasm and outcome in patients with Fisher grade III subarachnoid hemorrhage: results of a phase II multicenter, randomized, clinical trial. Stroke 2008, 39:|759-65.

Changes Clinical Practice

FI000 Factor 6.0 Must Read

Evaluated by Marek Mirski 05 Jun 2008 